\title{
Rheumatic Heart Disease in school going children: A cross-sectional epidemiological profile of Jajarkot, Nepal.
}

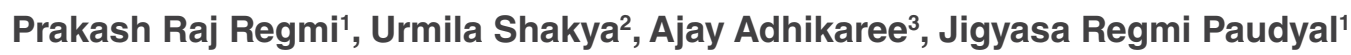

${ }^{1}$ Nepal Heart Foundation, Kathmandu, Nepal

${ }^{2}$ Shahid Gangalal National Heart Center, Kathmandu, Nepal

${ }^{3}$ National Academy of Medical Sciences, Bir hospital

Corresponding Author: Prakash Raj Regmi

Nepal Heart Foundation, Kathmandu, Nepal,

E-mail:pregmi68@gmail.com

ORCID ID NO: 0000-0002-2197-2672

Cite this article as: Regmi P.R., Shakya U., Adhikaree A., et al. Rheumatic Heart Disease in school going children: A cross-sectional epidemiological profile of Jajarkot, Nepal. Nepalese Heart Journal 2019; Vol 16 (2), 1-4

Submission date: $16^{\text {th }}$ July 2019

Accepted date: $31^{\text {st }}$ August 2019

\section{Abstract}

Background and Aims: Rheumatic Heart Disease (RHD) is the most common heart disease among children and young adults in Nepal. Identifying the prevalence of RHD is important in planning RHD prevention program. There are few studies on RHD conducted among children of unreached population of Nepal. This study aimed to determine the epidemiological status of RHD among school going children living in rural and underdeveloped community of Jajarkot, Nepal.

Methods: This is a cross-sectional study of 6,147 school going children of age group 5 to 16 years from 24 randomly selected schools of Jajarkot in the month of May, 2018. A team of cardiologists from Nepal Heart Foundation examined the children. Diagnosis of RHD was confirmed by echocardiography. Selected socio-demographic data were collected. All positive cases were reviewed by senior cardiologist. Information obtained were analyzed. Frequency and percentage for the categorical data were calculated. Prevalence was reported as cases per thousand school children.

Results: The overall prevalence of RHD was 7.32 per 1000 schoolchildren. Borderline RHD was 1.30 per 1000 and definite RHD 6.02 per 1000. On severity scale, mild RHD was 6.18, moderate RHD 0.81 and severe RHD 0.33 per 1000 respectively. Prevalence of RHD varied with age, sex, ethnicity, and severity. RHD was found higher among males, 10-16 years age group and underprivileged children.

Conclusion: Jajarkot is found to be a RHD endemic zone in Nepal where prevention efforts should be initiated urgently.

Keywords: Epidemiological study, Jajarkot, Rheumatic Heart Disease.

DOI: https://doi.org/10.3126/njh.v16i2.26293

\section{Introduction}

Rheumatic Heart Disease (RHD) is the most common heart disease in children of developing nations ${ }^{1-5}$ and connotes a chronic heart condition by virtue of acute rheumatic fever (ARF). ARF is the result of preceding group A Streptococcal throat infection. No specific treatment for RHD exists but, if detected early, continuous antibiotic prophylaxis (also known as "secondary prophylaxis" of RHD) can decrease ARF attack rates and mitigate the progression of $\mathrm{RHD}^{6,7}$.

With excess of overcrowding, malnutrition, poor sanitation/ ventilation, RHD continues to be an important public health concern in developing nation like Nepal. RHD accounts for top three reasons for admission in cardiology department and second most common cause for cardiac surgery at Shahid Gangalal National Heart Center (SGNHC) ${ }^{8}$. Variability occurs in the prevalence of RHD; from one country to another and within the country between people of different socio-economic strata ${ }^{9}$. Literatures on RHD for last three decades are sparse and display prevalence between 0.9 to 1.6 per thousand school going children ${ }^{10-16}$. To boot, the current statistics of RHD might reckon only a portion of a large burden of RHD with more RHD cases residing in rural setting which has not yet been covered by all these studies. Likewise, most of RHD demography are based on population-based birth defect registries or clinical symptoms guided diagnosis ${ }^{5}$. Limited population-based, large-sample study

(a) Nepalese Heart Journal. Nepalese Heart Journal retain copyright and works is simultaneously licensed under Creative Commons Attribution License CC - By 4.0 that allows others to share the work with an acknowledge of the work's authorship and initial publication in this journal 
on RHD using echocardiography has been conducted in Nepal. Thus, specific objective of this study was to access epidemiological status of RHD among school going children of Jajarkot district with general objective of educating students the link between streptococcal throat infection and rheumatic fever thus helping in planning care and management of potentially large number of children with RHD, particularly among unreached population.

\section{Materials and Methods}

Study Setting, design, procedure and data collection

Jajarkot is one of the ten districts of Karnali province which is the largest province of Nepal. It is mostly rural, least developed as well as most remote upper hilly district. Administratively it is divided into 3 municipalities and 4 rural municipalities with a population of 171,304 and population density of $77 / \mathrm{km}^{2}$ (200/sq mi) in accord with 2011 Nepal census and shares customarily tropical and temperate climate.

This cross-sectional RHD survey was undertaken in the month of May, 2018 and targeted school going children of Jajarkot district. 24 different schools both public and private were randomly incorporated and all students of age group 5-16 years were included embracing randomized cluster sampling technique. Students from private schools were considered as privileged and those from public schools as underprivileged. This survey was conducted under the banner of Nepal Heart Foundation (NHF) and essential ethical clearance was obtained from Institutional Review Board, NHF. Aforetime of survey, the foundation had corresponded and coordinated with principals of these schools and local authorities regarding date and general outline of the survey so as to consolidate maximum attendance for survey. A team of experienced cardiologists, physicians, nurses, health assistant and other administrative staffs visited respective schools on predefined date and time. Informed written consents from principals of respective schools were compiled. In like manner, verbal consent from each student or their parent was taken. A total of 6,147 students assembled up for the study.

Survey started with screening of high risk students likely to have ARF and RHD. Team of nurses, health assistants and administrative staffs were mobilized with individual tasks. Students with history of recurrent sore throat infection, chest wall deformity, congenital illness and those already diagnosed with RHD or on regular penicillin for RHD secondary prophylaxis were directly sent for echocardiography. Remaining students were queued up in rows for needful examination by team of physicians and cardiologists. A brisk physical examination focusing on cardiovascular system with mandatory auscultation of heart sound was done with the help of a stethoscope for each student. Students having normal examination findings were released. Students with heart murmur of grade one or more were subjected to echocardiographic examination which was performed by an experienced cardiologist with a battery operated SonositeMicromaxx portable ultrasound machine attached with SonoSite C11e curved (8-5 $\mathrm{MHz}$, Pediatric cardiac transducer. Absent students were traced for screening examination next day. Altogether we could cover $90 \%$ of the total admitted children. 2012 World Heart Federation criteria for echocardiographic diagnosis of $\mathrm{RHD}^{17}$ was pursued for defining RHD. The Australian RHD guideline $2012^{18}$ was used to define the severity of RHD. Students with borderline RHD, definite RHD with severity of illness and congenital heart disease were established and their relevant details including socioeconomic profile were assembled from school registry and documented in our record book. Secondary prophylaxis with Oral Penicillin V and other necessary medications were allotted to definite RHD cases along with yearly echocardiography follow up advice to borderline RHD cases. Severe RHD cases, and congenital heart disease requiring corrective surgery were instructed to visit foundation's clinic situated at Lalitpur, Nepal as early as possible. Students attending foundation's clinic requiring surgical assistance were referred to SGNHC or Manmohan Cardiothoracic Vascular and Transplant Center (MCVTC) for further consultation and needful surgery. Necessary arrangements for travel and treatment were made by NHF.

Meanwhile, a RHD educator explained the causal relationship of streptococcal throat infection and RHD to all the students, teachers and school personals before wrapping up with message of treating all streptococcal throat infection. Students with RHD were steered to take medicine regularly, have regular cardiac check up with annual echocardiography and visit nearby hospital in case of sore throat for needful treatment. The whole survey was supervised by a senior cardiologist.

\section{Statistical analysis}

Data were listed in excel sheet and analysis of acquired data was performed using Statistical Package for Social Sciences (SPSS) version 23.0. Categorical variables were depicted as number or percentage while continuous variables were formulated as mean, standard deviation and confidence interval. Prevalence was reported as cases per thousand school children. Results were also stratified between various stratas eg, public Vs private school and privileged Vs underprivileged ethnic groups.

\section{Results}

Out of 6147 children, $3278(53.33 \%)$ were males and 2869 $(46.67 \%)$ were females, $4166(67.77 \%)$ were from public schools and 1981 (32.23\%) were from private schools (Table 1). The prevalence of RHD was found to be 7.32 per 1000 children. Among males the prevalence was 9.73 per 1000 compared to 5.05 per 1000 in females (Figure 1). 265 children had heart murmur on auscultation who were subjected to echocardiography test. Total 45 children were found to have RHD. Out of them 8 had borderline RHD and 37 had definite RHD. Prevalence of mild RHD was 6.18 per 1000 compared to moderate RHD 0.81 and severe RHD 0.33 per 1000 respectively (Table 2). The most common lesion was mitral regurgitation (MR) followed by mitral stenosis (MS) and aortic regurgitation (AR). We found 31 children with isolated MR, 6 with combined MR and MS, 3 with isolated MS, 3 with combined MR, MS, AR and 2 with isolated AR (Table 3). Only 12 (26.66\%) children with RHD gave positive history of ARF. Prevalence of RHD varied with age, sex, ethnicity, and severity. RHD was found higher among males, 10-16 years age group and underprivileged children (Table 4). We found 19 (3.09 per 1000) children with Congenital heart diseases (CHD). Out of them 17 had acyanotic and 2 had cyanotic CHD

Table 1: Baseline demography

\begin{tabular}{|llll|}
\hline Sex & Affiliation & Number of children \\
\hline & $\begin{array}{l}\text { Public School } \\
\mathbf{( \% )}\end{array}$ & $\begin{array}{l}\text { Private school } \\
\mathbf{( \% )}\end{array}$ & Total (\%) \\
\hline Male & $2186(52.47)$ & $1092(55.12)$ & $3278(53.33)$ \\
\hline Female & $1980(47.53)$ & $889(44.88)$ & $2869(46.67)$ \\
\hline Total & $4166(67.77)$ & $1981(32.23)$ & 6,147 \\
\hline
\end{tabular}


Figure 1: Prevalence of RHD

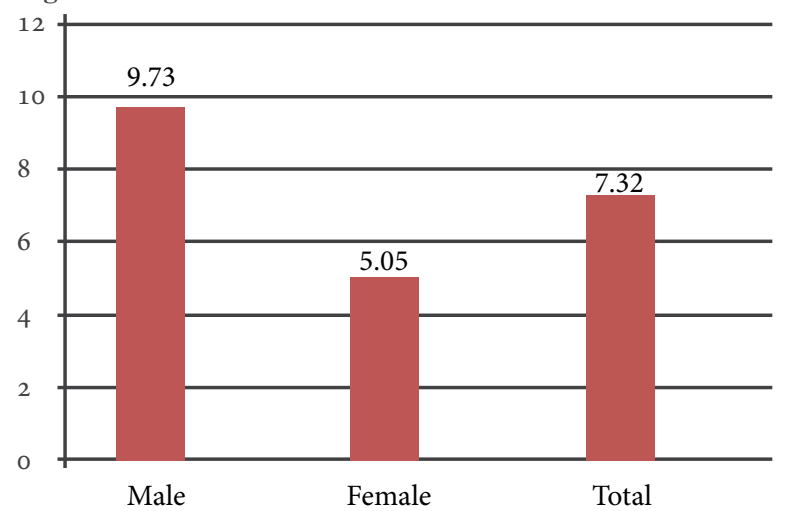

Table 2: Types and severity of RHD

\begin{tabular}{|lllll|}
\hline Characteristics & Male & Female & Total & $\begin{array}{l}\text { Prevalence per } \\
\text { Thousand }\end{array}$ \\
\hline Types of RHD & & & & \\
\hline $\begin{array}{l}\text { Borderline } \\
\text { Definite }\end{array}$ & 6 & 2 & 8 & 1.32 \\
Severity of RHD & 23 & 14 & 37 & 6.00 \\
\hline Mild & 26 & 12 & 38 & 6.18 \\
Moderate & 3 & 2 & 5 & 0.81 \\
Severe & 0 & 2 & 2 & 0.33 \\
\hline
\end{tabular}

Table 3: Types of valvular lesions

\begin{tabular}{|llll|}
\hline Characteristics & Male & Female & Total \\
\hline Isolated MR & 22 & 9 & 31 \\
\hline Isolated MS & 2 & 1 & 3 \\
\hline Isolated AR & 1 & 1 & 2 \\
\hline Combined MR, MS & 3 & 3 & 6 \\
\hline Combined MR, MS, AR & 1 & 2 & 3 \\
\hline
\end{tabular}

Table 4: Stratification of RHD status

\begin{tabular}{ll} 
Age group & Number of RHD Cases $(\%)$ \\
\hline $5-9$ years & $13(28.89)$ \\
$10-16$ & $32(71.11)$
\end{tabular}

\begin{tabular}{ll} 
Sex of the Children & $29(64.44)$ \\
Male & $16(35.56)$ \\
Female & \\
\hline Ethnic Category & $17(37.78)$ \\
\hline Privileged & $28(62.22)$ \\
\hline Underprivileged &
\end{tabular}

\section{Discussion}

This study tried to determine epidemiological characteristics of RHD among school going children of Jajarkot, a least developed unreached district in Karnali Province, Nepal. This is the first study covering large number of school children from rural area. High prevalence of RHD was detected which was 7.32 per thousand school children. On further stratifying, definite RHD were much more than borderline RHD (37 Vs 8), prevalence of mild RHD was 6.18 per thousand compared with moderate $(0.81$ per 1000$)$ and severe RHD (0.33 per 1000). Antecedent studies from other parts of Nepal showed prevalence ranging between 0.9 to 1.6 per thousand school going children $^{10-16}$. Conflictingly lower values were reported in various studies from different Asian countries ${ }^{2,19,20}$. This study established a higher prevalence of RHD among school going children in Jajarkot district seemingly interpreted by low health awareness, and poverty in the area.

Rheumatic Heart Disease was found higher among males, 10-16 years age group and underprivileged ethnic groups of children. Very limited studies are available in Nepalese context which are analogous with similar findings of higher prevalence in males ${ }^{21}$ compared with females and among underprivileged groups compared with privileged ones as buttressed by studies from India ${ }^{22}$, Thailand ${ }^{1}$ and Bangladesh ${ }^{23}$. Parallel with our study, the prevalence of RHD was found higher among older age group children in studies from eastern $\mathrm{Nepal}^{21}$, North India $^{24}$ and Senegal ${ }^{25}$. Such a status may underscore the importance of cumulative exposure to progression of disease. Although there are very few studies documenting RHD demographics, this study advocates the need for large sample based studies to explore prevalence and associated factors of RHD, particularly in remote districts of Nepal.

This study paints an alarming status of high prevalence of RHD in resource constrained environment of Jajarkot, where access to health care is very minimal. Such screening program among school going children can play a vital role in early detection and preventing further deterioration from heart diseases like RHD. Over and above, this study outlook the opportunity to incorporate capacity-building for local health service providers and to launch primary and secondary prevention programs in health facilities. This survey has proven to be effective in early detection and timely treatment of valvular heart disease which undoubtedly will contribute to reducing burden of illness by reducing need for surgery. Thus the authors summon upon actively prioritizing such approach of prevention strategy whenever possible for reducing prevalence of RHD and economic burden in rural Nepal even if it requires greater investment in time and other resources.

This study had few limitations. First, the study was confined only to Jajarkot district and results cannot be generalized to other parts of Nepal. Second, the actual time of occurrence of RHD is uncertain. Temporal changes in disease prevalence would have been best described by continuous longitudinal data collection. Third, the observed prevalence of RHD among school going children may represent just tip of an iceberg; representing only a fraction of all cases in the community. This is a clinical screening study, not an echo screening. If echo screening was performed, much more cases would have been detected. Therefore, it is imperative to consider such limitations while interpreting findings of this study.

\section{Conclusion}

Compared to Kathmandu city, Jajarkot has 7 times higher prevalence rate of RHD among school going children (7.12 Vs 0.9 per 1000). This is the highest RHD prevalence detected by clinical screening reported till date in Nepal. We see urgent need to strengthen RHD care services and initiate RHD prevention efforts in this and similar areas of Nepal.

\section{Sources of funding: None} Conflict of Interest: None 


\section{References}

1. Chaikitpinyo A, Panamonta M, Wongswadiwat Y, et al. Rheumatic and congenital heart diseases among school children of Khon Kaen, Thailand: declining prevalence of rheumatic heart disease. Asian Biomedicine. 2014;8(5):645-50. https://doi.org/10.5372/1905-7415.0805.339

2. Marijon E, Ou P, Celermajer DS, Ferreira B, et al. Prevalence of rheumatic heart disease detected by echocardiographic screening. New England Journal of Medicine. 2007;357(5):4706. PMid: 17671255 https://doi.org/10.1056/NEJMoa065085

3. Mendis S, Puska P, Norrving B. Global atlas on cardiovascular disease prevention and control: World Health Organization; 2011. 62-66

4. Panamonta M, Chaikitpinyo A, Auvichayapat N, et al. Evolution of valve damage in Sydenham's chorea during recurrence of rheumatic fever. International journal of cardiology. 2007;119(1):73-9. PMid:17049647 https://doi.org/10.1016/j.ijcard.2006.07.077

5. Yu C-H, Lue H-C, Wu S-J, Chen M-R. Heart disease screening of schoolchildren in Taiwan. Archives of pediatrics \& adolescent medicine. 2009;163(3):233-7. PMid:19255390 https://doi.org/10.1001/archpediatrics.2008.562

6. Stollerman GH. The prevention of rheumatic fever by the use of antibiotics. Bulletin of the New York Academy of Medicine. 1955;31(3):165.

7. Stollerman GH, Rusoff JH. Prophylaxis against group A streptococcal infections in rheumatic fever patients: use of new repository penicillin preparation. Journal of the American Medical Association. 1952;150(16):1571-5. PMid:12990472 https://doi.org/10.1001/jama.1952.03680160021005

8. Annual Report of Shahid Gangalal National Heart Centre (2009, 2010, 2011, 2012, 2013, 2014, 2015).

9. Carapetis JR. Rheumatic heart disease in developing countries. New England Journal of Medicine. 2007;357(5):439-41. PMid: 17671252 https://doi.org/10.1056/NEJMp078039

10. Regmi PR, Pandey MR. Prevalence of Rheumatic Fever and Rheumatic Heart Disease in school children of Kathmandu city. Indian Heart J 1997; 49: 518-20

11. Bahadur K, Sharma D, Shrestha M, et al. Prevalence of rheumatic and congenital heart disease in schoolchildren of Kathmandu valley in Nepal. Indian heart journal. 2003;55(6):615-8.

12. Joshi A, Shrestha R, Shrestha P, et al. Pattern of Cardiac Diseases in Children Attended at Dhulikhel Hospital, Nepal. Kathmandu University medical journal (KUMJ). 2016;14(55):239-43.

13. Limbu Y, Maskey A. Current status of rheumatic fever and rheumatic heart disease in Nepal. Journal of Nepal Medical Association. 2002;41:514-7. https://doi.org/10.31729/jnma.720
14. Shrestha U, Bhattarai T, Pandey M. Prevalence of rheumatic fever and rheumatic heart disease in school children in a rural community of the hill region of Nepal. Indian heart journal. 1991;43(1):39-41.

15. Prajapati D, Sharma D, Regmi PR, et al. Epidemiological survey of Rheumatic fever, Rheumatic heart disease and Congenital heart disease among school children in Kathmandu valley of Nepal. Nepalese Heart Journal. 2013;10(1):1-5. https://doi.org/10.3126/njh.v10i1.9738

16. Laudari S,Tiwari K, Pazdernik M, Sharma S. Rheumatic Heart Disease ScreeningAmong School Children in Central Nepal , J A C C : Case Reports vol.1 number 2, Aug 2019 https://doi.org/10.1016/j.jaccas.2019.06.023

17. RHDAustralia (ARF/RHD Writing Group). The Australian Guideline forPrevention, Diagnosis and Management of Acute Rheumatic Fever and Rheumatic Heart Disease. 2nd ed. National Heart Foundation of Australia and the Cardiac Society of Australia and New Zealand; 2012. page 58

18. Remenyi, B. et al. World Heart Federation criteria for echocardiographic diagnosis of rheumatic heart disease-an evidence-based guideline. Nat. Rev. Cardiol. 9, 297-309 (2012).61. Lennon, D., Kerdemelidis, M. \& Arroll, B. PMid:22371105 PMCid:PMC5523449 https://doi.org/10.1038/nrcardio.2012.7

19. Jose VJ, Gomathi M. Declining prevalence of rheumatic heart disease in rural schoolchildren in India: 2001-2002. Indian heart journal. 2003;55(2):158-60.

20. Periwal K, Gupta B, Panwar R, et al. Prevalence of rheumatic heart disease in school children in Bikaner: an echocardiographic study. JAPI. 2006;54:279-82.

21. Shrestha NR, Karki P, Mahto R, et al. Prevalence of subclinical rheumatic heart disease in eastern Nepal: a schoolbased cross-sectional study. JAMA cardiology. 2016;1(1):8996. PMid:27437661

https://doi.org/10.1001/jamacardio.2015.0292

22. Grover A, Dhawan A, Iyengar S, et al. Epidemiology of rheumatic fever and rheumatic heart disease in a rural community in northern India. Bulletin of the World Health Organization. 1993;71(1):59.

23. Islam AM, Majumder A. Rheumatic fever and rheumatic heart disease in Bangladesh: A review. Indian Heart Journal. 2016;68(1):88-98. PMid:26896274 PMCid:PMC4759488 https://doi.org/10.1016/j.ihj.2015.07.039

24. Negi PC, Kanwar A, Chauhan R, et al. Epidemiological trends of RF/RHD in school children of Shimla in north India. The Indian journal of medical research. 2013;137(6):1121.

25. Kane A, Mirabel M, Touré K, et al. Echocardiographic screening for rheumatic heart disease: age matters. International journal of cardiology. 2013;168(2):888-91. PMid:23245622 https://doi.org/10.1016/j.ijcard.2012.10.090 